eISSN: 2659-6482

DOI: https://doi.org/10.14201/pmrt.20650

\title{
'I VITELLONI' COMO PRIMERA ETAPA EN LA EXPRESIÓN DEL SENTIMIENTO DE NOSTALGIA EN LA MÚSICA QUE NINO ROTA COMPUSO PARA EL CINE DE FEDERICO FELLINI
}

\section{'I vitelloni' as a First Stage in the Expression of the Feeling of Nostalgia in the Music that Nino Rota Composed for the Cinema of Federico Fellini}

\author{
Ignacio SAAVEDRA INARAJA \\ Universidad CEU San Pablo \\ igsaavedra@ceu.es
}

RESUMEN: Este artículo analiza en profundidad la música de una de las primeras películas de Federico Fellini: I vitelloni (1953). Es la primera parte de un estudio que quiere recorrer las películas con claro contenido autobiográfico entre las dirigidas por Federico Fellini. Esta parte de su filmografía no es en absoluto marginal, puesto que incluye cerca de la mitad de los filmes dirigidos por «Il Maestro", entre ellos algunas de sus obras maestras, como La dolce vita u Otto e mezzo. La metodología combina, fundamentalmente, el análisis audiovisual y el análisis textual.

Palabras clave: Fellini; Nino Rota; I vitelloni; Música cinematográfica.

ABSTRACT: This article analyses in depth the music of one of Federico Fellini's first films: I Vitelloni (1953). It is the first part of a study that wants to go through films with clear autobiographical content among those directed by Federico Fellini. This part of his filmography is not at all marginal, since it includes about half of the films directed by "Il Maestro», among them some of his masterpieces, such as La dolce vita or Otto e mezzo. The methodology combines, mainly, audiovisual analysis and textual analysis.

Keywords: Fellini; Nino Rota; I vitelloni; Film Music. 
IGNACIO SAAVEDRA INARAJA

'I VITELLONI' COMO PRIMERA ETAPA EN LA EXPRESIÓN DEL SENTIMIENTO DE NOSTALGIA

EN LA MÚSICA QUE NINO ROTA COMPUSO PARA EL CINE DE FEDERICO FELLINI

\section{INTRODUCCIÓN}

Este artículo podría considerarse la aceptación del reto que proponía hace algunos años uno de los grandes expertos en el estudio de Federico Fellini: Thomas Van Order, profesor de Middlebury College, en Vermont (Estados Unidos). En su estudio Listening to Fellini (Van Order, 2009), en el que hacía una descripción general de la música de las películas que Fellini rodó en blanco y negro, proponía a la comunidad académica la realización de investigaciones que estudiaran el recorrido de algún aspecto de la música de Fellini a lo largo de su filmografía. La propuesta venía justificada por la demostración de que la colaboración entre el director Federico Fellini y el compositor musical Nino Rota configuraban una unidad, como una sola gran obra dividida en varias partes.

Elegimos la expresión del sentimiento de nostalgia a través de la música porque, al tratarse de un cine muy autobiográfico, la nostalgia es un sentimiento muy presente, lo que daba pie a un análisis musical relacionado con algunas de las principales funciones de la música cinematográfica. Era, por tanto, una ocasión de aplicar a un caso concreto algunos avances recientes en el estudio de las funciones de la música cinematográfica.

Dicho estudio, que pretende continuar en el futuro con el análisis en profundidad de, al menos, otras seis películas de Fellini, debía empezar por I vitelloni, primera película en que Fellini decide explotar el filón autobiográfico y que, por tanto, pone las bases, tanto cinematográficas como musicales, de su colaboración con Nino Rota en esa parte concreta de su filmografía.

\section{EL BINOMIO ROTA-FELLINI}

La colaboración entre Federico Fellini y Nino Rota es un caso único en la historia del cine. Solo la muerte de este último pudo poner fin a una relación profesional que había empezado en 1952, cuando Nino Rota fue el encargado de componer la música para Lo sceicco bianco. Era la primera película que Fellini dirigía en solitario, después de haber filmado, en colaboración con Alberto Lattuada, Luci del Varietà. Desde entonces, y hasta la muerte del músico, Nino Rota fue el autor de la música de todos los filmes de Fellini, quien tuvo siempre palabras muy elogiosas sobre lo mucho que Nino Rota aportó a sus películas: «el más valioso de todos mis colaboradores, puedo contestar sin necesidad de reflexionar, fue Nino Rota. Entre nosotros hubo enseguida un entendimiento pleno, total, desde el Sceicco bianco, primer filme que hicimos juntos. Nuestro entendimiento no tuvo necesidad de 'rodaje'. Yo me había decidido a ser director y Nino era ya la condición para que siguiera siéndolo» (Grazzini, 2006, p. 120). 
IGNACIO SAAVEDRA INARAJA

'I VITELLONI' COMO PRIMERA ETAPA EN LA EXPRESIÓN DEL SENTIMIENTO DE NOSTALGIA

EN LA MÚSICA QUE NINO ROTA COMPUSO PARA EL CINE DE FEDERICO FELLINI

\section{LA NOSTALGIA EN EL CINE DE FELLINI}

El sentimiento de nostalgia está muy presente en el cine de Federico Fellini porque, como ha explicado con profusión el profesor Colón Perales (1994), el cine de Fellini es «esencialmente memorialístico». Ese carácter memorialístico, esa presencia de lo autobiográfico, empieza en la película que analizamos en este artículo y va evolucionando hasta culminar en su penúltimo largometraje, Intervista (1987). El relativo éxito de I vitelloni facilitó que Fellini decidiera seguir explotando el filón autobiográfico, clave de algunas de sus obras maestras, como La dolce vita (1959), Otto e mezzo (1963) o Amarcord (1973).

\section{La expresión de sentimientos en la música cinematográfica}

Muchos autores han explicado de modo convincente que una de las principales funciones de la música cinematográfica es servir de vehículo de emociones. Entre las investigaciones que han contribuido a explicar esta idea destaca la de Annabel J. Cohen, que plasmó el fruto de su trabajo en un artículo titulado La música como fuente de emoción en el cine (2011). Como explica Cohen en el artículo citado, resulta mucho más fácil hablar de la expresión de sentimientos en la música cinematográfica que en la música autónoma. La razón es que el contexto narrativo en el que se inserta la música cinematográfica ayuda a establecer un objeto. Sin un objeto claro, es muy difícil asociar una determinada música con un sentimiento o una emoción. «Por ejemplo, el sentimiento de alivio requiere un objeto, como puede ser el final feliz de un viaje lleno de peligros» (p. 250), explica Cohen.

La música puede cumplir muchas y muy distintas funciones cuando se une a la imagen. Una de ellas es la expresión de sentimientos. Esa expresión de sentimientos puede ayudar a que la historia sea mejor asimilada. Desde otro punto de vista, puede ayudar a captar la atención del espectador, haciéndole compartir los sentimientos de los personajes de la historia.

Según Teresa Fraile (2004, p. 12), «en el cine existe un fluido continuo entre música, film y espectador, donde no sólo la música apela a la emotividad del espectador, sino que se dibuja como la forma concreta de sus emociones». Como iremos viendo en el análisis de la expresión de la nostalgia en I vitelloni, este proceso, este fluido, opera en una doble dirección, pero de una manera que puede variar mucho.

Esa doble dirección es, obviamente, emisor-receptor. La música puede ser la expresión del sentimiento de nostalgia del director o del guionista de la película. Desde el otro punto de vista del proceso, la música puede provocar un sentimiento de nostalgia en el espectador de la película. En medio del proceso, la música puede expresar el sentimiento de nostalgia de los protagonistas de la historia. Los creadores y los receptores de la historia pueden o no compartir ese sentimiento. 
Para entender con más precisión el proceso por el que la música cinematográfica contribuye a la expresión de sentimientos, creemos que puede ser oportuno resumir la explicación de Teresa Fraile sobre las distintas funciones expresivas de la música cinematográfica. Según la profesora Fraile, las principales funciones expresivas de la música cinematográfica son seis:

- Nexo con el espectador.

- Marco.

- Realismo.

- Tono emotivo.

- Subrayado dramático o expresivo.

- Identificación con un personaje. (Fraile, 2004, pp. 15-19).

Las tres primeras funciones citadas sirven, según Fraile, para facilitar la recepción del mensaje de la película por parte del espectador, predisponiéndolo a introducirse en el contenido fílmico. Las dos segundas, que son las que tienen una relación más directa con nuestro trabajo, son las funciones expresivas «donde predomina el contenido emocional» (Fraile, 2004, p. 17). Es en esas dos funciones expresivas donde pretendemos encuadrar la expresión del sentimiento de nostalgia en la música que Nino Rota compuso para el cine de Federico Fellini.

La expresión del tono emotivo general de una escena o de una película en su totalidad es, como subraya Teresa Fraile, «una de las funciones más características, más evidentes, y más puestas de relevancia, tanto por estudiosos como por aficionados» (Fraile, 2004, p. 17). No es necesario, por tanto, detenerse en tratar de demostrar que la música cinematográfica cumple esa función. Lo que nos parece pertinente ahora es destacar que ese tono emotivo puede estar implícito en la narración o no, es decir: «puede ser la propia música la que indique desde qué perspectiva emotiva han de leerse las imágenes» (Fraile, 2004, p. 17).

La segunda función de la música cinematográfica entre aquellas en las que predomina el contenido emocional es, siempre según la misma autora, el subrayado dramático o expresivo, es decir: «la participación de la música cuando cumple una función de intensificador de sentimientos» (Fraile, 2004, p. 17). Como en la función anteriormente citada, el sentimiento contenido en la narración es expresado por la música, pero de un modo más puntual, porque el contenido emotivo queda en evidencia por los otros elementos del lenguaje cinematográfico.

Para resaltar la importancia de la música en los aspectos emocionales del film, Annabel Cohen destaca que, de las ocho funciones que se suelen atribuir a la música cinematográfica, seis tiene alguna relación con lo emocional (2011, p. 258).

Según el planteamiento de Cohen, hay dos razones principales, más allá de lo obvio, por las que la música cinematográfica tiene tanto poder en el plano de los 
afectos, las emociones, los sentimientos. En primer lugar, porque toda la creación cinematográfica en su conjunto tiene un propósito emocional: la unión afectiva entre el espectador y la pantalla. Podríamos decir que la creación cinematográfica busca, en última instancia, seducir, enamorar al espectador.

En segundo lugar, la capacidad de la música, considerada en sí misma, para conmover, se debe a que, en cada pieza musical, en cada fragmento, en cada compás, hay simultáneamente muchas fuentes de emoción. Esas fuentes de emoción son los distintos elementos en que tradicionalmente se ha dividido la música: melodía, armonía, ritmo y timbre. Cada uno de ellos por sí solo transmite emoción. Cohen (2011, p. 266) lo expresa así:

La capacidad que posee la música para cumplir con tareas emocionales, mucho mayor que la capacidad que tiene la imagen, puede estar basada en la habilidad de la música para portar simultáneamente muchos tipos de información emocional a través de la melodía, el ritmo, el timbre, la armonía y la tonalidad.

\section{I vitelloni}

Se trata de la segunda película del binomio Rota-Fellini. El comienzo del rodaje llegó en un momento muy delicado, después del relativo fracaso de Lo sceicco bianco. ¿Qué habría pasado en caso de que esta película tampoco hubiese triunfado? Imposible saberlo, pero no cabe duda de que el futuro de Fellini como director habría quedado muy en entredicho. Por suerte para el séptimo arte, un león de plata para I vitelloni en la Mostra de Venecia de 1953 supuso el espaldarazo necesario para que Fellini sintiera definitivamente que podía hacer de la dirección cinematográfica su modo de vida.

El punto de partida del trabajo de Nino Rota para esta película se resume en esta cita:

He buscado atenerme en lo posible a la máxima sencillez. Este filme de personajes aparentemente sencillos y de argumento casi diría que frágil, tiene sin embargo una notable complejidad de matices y de significados. De acuerdo con Fellini, he evitado confiar a la música la tarea de interpretarlos literalmente. Espero haber conseguido acentuar el carácter de melancolía y de participación humana que, me parece, constituye el lado más sentido y poético del film (Latorre, 1989, p. 111).

En el momento de su estreno, los críticos empiezan a descubrir con claridad los rasgos principales de quien acabará siendo uno de los mayores genios de la Historia del Cine. Así, Arturo Lanocita escribía en Il corriere della sera:

Aunque no conociéramos su actividad pasada [...], bastarían pocas tomas para dejar patente que Federico Fellini es un humorista. Pero un humorista melancólico, 
IGNACIO SAAVEDRA INARAJA

'I VITELLONI' COMO PRIMERA ETAPA EN LA EXPRESIÓN DEL SENTIMIENTO DE NOSTALGIA

EN LA MÚSICA QUE NINO ROTA COMPUSO PARA EL CINE DE FEDERICO FELLINI

haya o no contradicciones. Sonríe, pero con amargura. Está claro que el pequeño mundo gandul y turbulento que describe le da la misma impresión desagradable que nos da a nosotros, un mundo de criaturas malgastadas, de existencias superfluas. Lo comprende, lo estudia; no diría que lo humilla; tal vez, lo compadece. Pero es evidente que busca con ironía el contraste entre el mucho presumir y el despreciable ser (Lanocita, 1953, s. p.).

Esos rasgos, que aparecen tan claros en los albores de la trayectoria felliniana, coinciden con los rasgos de la música compuesta por Nino Rota para el director riminés. Esa sonrisa amarga, esa ironía, esa mirada compasiva hacia las debilidades humanas, son notas características que los críticos musicales atribuyen a Rota cuando intentan descubrir qué es lo que transmite la música que escribió para el cine de Fellini.

Tiene especial interés para nuestra investigación la relación entre el argumento de la película y la biografía de Fellini. Se trata de la primera vez en que Fellini decide hablar de sus recuerdos. Inicia así una línea de trabajo que será constante a lo largo de su trayectoria. Es probable que en el momento de empezar el rodaje de $I$ vitelloni no estuviera muy seguro de si desnudar el alma de una manera tan «impúdica» fuera lo más adecuado. Sea como fuere, veinte años después, con mucha más perspectiva, pareció reconocer que esas historias directamente inspiradas en su propia vida habían sido un factor clave en su éxito. Nos referimos a las palabras dichas por Fellini durante una entrevista concedida a un periodista italiano justo después de conocerse la noticia de que Amarcord había recibido el Óscar a la mejor película en lengua extranjera (AA. VV., 2000, p. 87).

Era previsible que Fellini empezara muy pronto a explotar el filón autobiográfico en sus películas. Había probado a hacerlo en su época de dibujante y escritor humorístico, y había descubierto que podía funcionar. Fellini empezó a trabajar en la revista Marc'Aurelio en marzo de 1939. Según Tullio Kezich (2007, p. 43),

Fellini aprovecha que el periódico le concede cada vez más espacio - llega a publicar hasta tres o cuatro textos en un mismo número - para redactar unas auténticas memorias de su vida en provincias, una especie de prefiguración de 'Amarcord'. Como hará luego en cine con los espectadores de todo el mundo, el narrador cautiva la atención de los jóvenes lectores gracias al tono íntimo y confidencial, a un humor a la vez ingenuo y avisado, y a esa implacable autoironía que lo guiará luego por los vericuetos psicoanalíticos de 'Ocho y medio'.

Fellini no tuvo ningún reparo en reconocer el carácter autobiográfico de $I$ vitelloni. Todo lo contrario. A lo largo de la película, uno de los vitellone, Moraldo, va dejando pistas que nos llevan a pensar en él como en un alter ego de Fellini. Justo al final de la película hay un detalle que no deja lugar a dudas. Como explica Tullio Kezich, «si nos fijamos bien, reconoceremos la voz que dice 'Adiós, Guido', 
IGNACIO SAAVEDRA INARAJA

'I VITELLONI' COMO PRIMERA ETAPA EN LA EXPRESIÓN DEL SENTIMIENTO DE NOSTALGIA

EN LA MÚSICA QUE NINO ROTA COMPUSO PARA EL CINE DE FEDERICO FELLINI

que ya no es la de Interlenghi [el actor que interpreta el papel de Moraldo], sino la del propio Fellini, que quiso doblar al actor para sellar su personal adiós a la juventud» Tullio Kezich (2007, p. 43).

\section{Argumento de I vitelloni}

I vitelloni retrata el modo de vida de un grupo de amigos en una ciudad italiana de provincias junto al mar. Hay mucho paralelismo con los amigos de infancia y adolescencia de Fellini en Rimini, pero no se trata de un calco de la realidad. Los vitellone son relativamente jóvenes, pero ya maduros, mientras que Fellini abandonó su ciudad natal siendo casi un adolescente. El más joven de la pandilla, Moraldo, podría ser considerado el primer «alter ego» de Fellini, como acabamos de comentar.

Fellini no fue nunca un vitellone porque se fue de Rimini antes de tener la oportunidad de serlo. Tenía muchas posibilidades de haber llegado a serlo, pero abandonó la pequeña ciudad costera de provincias a tiempo de evitarlo. Un vitellone tiene ya cierta edad; la compasión que inspira se debe a que, en general, tiene un comportamiento y una actitud ante la vida propias de alguien que tiene quince o veinte años menos. En resumen: es el eterno adolescente, que está siempre esperando a que llueva del cielo la oportunidad de sentar la cabeza.

I vitelloni se tradujo al español como Los inútiles. Es obvio que no hay una traducción exacta. En la entrevista de José Luis de Vilallonga a Fellini (1994) se plantea que una traducción más exacta sería Los señoritos. Tampoco nos parece una traducción muy acertada. Para entender qué es un vitellone podemos recurrir a la explicación de Tullio Kezich: «Del riminés 'vidlòn', término con el que la gente que trabaja llama a los estudiantes, a los jovencitos burgueses de las localidades balnearias del Adriático y a los ociosos en general que van tirando entre veranos tórridos e inviernos soporíferos» (Tullio Kezich, 2007, p. 137).

Esther Benítez, traductora de la versión del guion de I vitelloni editada en Alianza Editorial indica que «aparece en la filmografía de Fellini como Los inútiles y también es conocida como Los gamberros. La verdad es que ni una ni otra palabra expresan enteramente el significado de vitellone, que se acerca más al de 'calavera', señorito tarambana» (traducción de Esther Benítez en Fellini, 1972, p. 133).

Los vitelloni son cinco: Fausto (Franco Fabrizi), Moraldo (Franco Interleghi), Ricardo (Ricardo Fellini), Alberto (Alberto Sordi) y Leopoldo (Leopoldo Trieste). La presentación al espectador, con la voz en off del propio Fellini, se produce en la primera escena, la del concurso «Miss Sirena 1953». Fausto aparece, por supuesto, intentando seducir a una mujer, que le pregunta por Sandra. Fausto asegura haber olvidado a Sandra. Por esta razón resulta después tan dramático saber que Sandra está embarazada como fruto de su relación con Fausto. Ricardo 
aparece amenizando la fiesta con su voz, que canta la melodía del tema principal de la película. Mientras tanto, la voz en off y un travelling de la cámara presentan rápidamente a Alberto, Leopoldo «el intelectual» y Moraldo, este último un poco al margen de los otros desde el primer momento.

Sandra, la hermana de Moraldo, es proclamada Miss Sirena 1953. Justo en el momento de la proclamación se desata una gran tormenta que obliga a los asistentes a la fiesta a refugiarse en el interior del recinto. Sandra, emocionada y rodeada por una multitud que acude a felicitarla, sufre un desmayo. Es llevada aparte, y el médico que acude a asistirla parece querer comunicar algo grave que, de momento, parecen entender solo Moraldo y Fausto. Poco a poco iremos descubriendo que lo que ha descubierto el médico es el embarazo de Sandra.

Fausto acude rápidamente a su casa a hacer las maletas. Al poco tiempo llega Moraldo y le confirma lo que él ya sospecha. Entretanto, la noticia ha llegado al padre de Fausto que, después de una durísima reprensión, deja bien claro a su hijo que debe casarse con Sandra.

Moraldo es, probablemente, el primer alter ego de Fellini, como luego lo serán los protagonistas de La dolce vita y de Otto e mezzo, ambos encarnados por el actor Marcello Mastroianni. Moraldo aparece desde el primer momento como «el vitellone menos vitellónico». En la fiesta para la elección de Miss Sirena, mientras los demás se comportan con una actitud más bien frívola, él se queda extasiado contemplando el espectáculo que ofrece la naturaleza: «He aquí a Moraldo, el más joven de la pandilla. Moraldo, sentado en la barandilla metálica de la terraza, mira absorto el cielo. Después se dirige a sus camaradas: 'Eh, mira qué bien, está relampagueando'» (traducción de Esther Benítez en Fellini, 1972, p. 137). Tiene cierta importancia que el narrador destaque que es el más joven, porque eso le convierte en el principal candidato a dar el salto a una vida con un horizonte más amplio que el que ofrece la pequeña ciudad de provincias.

Moraldo es siempre el «Pepito Grillo» del grupo, el que siempre intenta que el comportamiento de sus amigos no supere ciertos límites. Así, una noche le pide a Alberto que deje de incordiar a una prostituta con la que se encuentran por la calle. También reprocha a sus amigos que se burlen de Fausto cuando este se encuentra trabajando en la tienda del amigo de su suegro.

Moraldo queda en una situación tremendamente incómoda tras el acontecimiento que da un giro radical a los acontecimientos: el embarazo de Sandra, su hermana, como consecuencia de su relación con Fausto. Incluso tiene que soportar la prueba de ser testigo de las infidelidades de su cuñado. Poco antes de tomar definitivamente la decisión de marcharse de la ciudad, tiene un serio altercado con Fausto. Sandra estaba desaparecida. Harta de las infidelidades de Fausto, ha salido de su casa con el bebé, y nadie sabe dónde está. Fausto llega a casa; allí se encuentra con Moraldo y le dice: «Si no vuelve me mato», a lo que Moraldo 
IGNACIO SAAVEDRA INARAJA

'I VITELLONI' COMO PRIMERA ETAPA EN LA EXPRESIÓN DEL SENTIMIENTO DE NOSTALGIA

EN LA MÚSICA QUE NINO ROTA COMPUSO PARA EL CINE DE FEDERICO FELLINI

responde: «¿Tú? Tú no te matas. Eres un cobarde» (traducción de Esther Benítez en Fellini, 1972, p. 270).

\section{Sobre el carácter autobiográfico de I vitelloni}

Detengámonos ahora en algunos aspectos de la relación entre la vida de Fellini y el argumento de la película. El carácter autobiográfico de la obra de Fellini se manifiesta de distintas maneras: lugares, acontecimientos históricos, vivencias más personales, etc. Pero, sobre todo, se manifiesta en lo que Colón Perales (1994, p. 34) llama «la representación de sí mismo. La 'barroca' inserción del creador en su obra». Esta inserción, según Colón Perales, se realiza de tres maneras: el «doble figurado», el «doble real» o el propio Fellini apareciendo en persona en sus películas.

El Moraldo de I vitelloni es, según la clasificación de Colón, el primer «doble real», antecedente de otros dobles reales posteriores interpretados por Marcello Mastroianni (Marcello en La dolce vita o Guido en Otto e mezzo, por ejemplo). Como explica Colón Perales (1994, p. 35), «tiene unas características físicas que se repetirán de film en film aunque sean varios los actores que lo incorporen». Como decíamos, se trata del aspecto físico de Marcello Mastroianni, pero también de los actores que tuvieron que interpretar a Fellini joven cuando Mastroianni ya tenía cierta edad.

La ciudad en que se desarrolla la acción de I vitelloni es la primera recreación de Rimini. Como explica el propio Fellini, «Había reencontrado Rimini en Roma, era Ostia. Allí he rodado I vitelloni, porque es una Rimini inventada: es más Rimini que la propia Rimini... Se trata de la reconstrucción escenográfica del país de la memoria» (Fellini, pp. 35-36). Aunque el mar que vemos en la película es el Tirreno y no el Adriático, no importa. La escena de los vitelloni paseando por la playa un día de invierno tiene un indudable carácter autobiográfico.

En I vitelloni empiezan a aparecer ambientes y personajes inspirados en los recuerdos de Fellini que serán recurrentes en filmes posteriores. Por ejemplo, ese pobre loco llamado Giudizio, aquí apenas esbozado, pero mucho más perfilado veinte años después en I clowns y Amarcord. Otro ejemplo destacado es la escena de la comida familiar que acaba en batalla campal. Como ocurrirá después en la famosa escena de Amarcord, aquí también es el cabeza de familia - el padre de Sandra y Moraldo - quien, en plena comida, intenta ajustar cuentas con su hijo. Por último, podríamos citar las escenas en que los amigos se reúnen en torno a la mesa de billar. 
IGNACIO SAAVEDRA INARAJA

'I VITELLONI' COMO PRIMERA ETAPA EN LA EXPRESIÓN DEL SENTIMIENTO DE NOSTALGIA EN LA MÚSICA QUE NINO ROTA COMPUSO PARA EL CINE DE FEDERICO FELLINI

\section{LA MÚSICA DE I VITELLONI}

Como ha hecho notar el profesor Thomas Van Order en su trabajo de investigación Listening to Fellini (2009), uno de los cambios que se dan en la música de I vitelloni con respecto a la primera película dirigida por Fellini es la gran distancia entre la percepción de la música por parte de los protagonistas de la película y la percepción de la música por parte de los espectadores de la película. De ahí se deriva también el hecho de que, cuando el espectador trata de entender el significado implícito en esa música, se presentan muchas posibilidades de lectura, lo que obliga al espectador a tener que realizar un esfuerzo suplementario, pero, al mismo tiempo, le proporciona una confortable libertad de interpretación. El espectador de I vitelloni percibe, casi siempre de modo inconsciente, que las opciones de lectura de la narración entre líneas dependen de su voluntad.

Otro aspecto destacable es la continua confusión entre el carácter diegético y no diegético de la música. En esto se ve también una notable evolución con respecto a Lo sceicco bianco, a pesar de que ya se había incoado ese recurso estilístico en la primera colaboración del tándem compositor-director. Como explica Roberto Cueto, «en una obra tan temprana como El jeque blanco las fronteras [entre música diegética y extradiegética] se diluyen: ¿es esa música bufa que escuchamos durante el rodaje de la fotonovela un fondo diegético o un comentario de Rota sobre la naturaleza fundamentalmente circense de esa actividad?» (Cueto, 2011, p. 151). El inconfundible tema principal aparece con frecuencia como música no diegética, pero su significado se enriquece con nuevos matices cuando se convierte en música diegética en un disco que escucha el vitellone Leopoldo o silbado por Fausto.

En general, el complejo trabajo musical realizado por Fellini en I vitelloni es una demostración de que el director riminés estaba empeñado en abrir nuevos caminos, en innovar, en buscar su propio estilo. Un ejemplo de esto es el uso de música compuesta expresamente para la película como música diegética. Se trataba de algo absolutamente inusual en el cine de Hollywood de aquella época (Van Order, 2009, p. 46).

\section{Los tres temas principales}

Como ocurre en otras películas de Fellini, los títulos de crédito sirven para presentar los temas principales de la música de la película, que después actuarán como leitmotiven a lo largo del metraje. También como en otros casos (Il bidone, La strada), se trata de tres motivos. No serán los únicos, como veremos más adelante.

Denominaremos «Tema de Alberto» al que suena en primer lugar, después de una brevísima secuencia en que se ve a los vitelloni cantando por la calle. Theodore Van $\operatorname{Order}(2009$, p. 41) ha calificado este tema musical como «misterioso, oscuro, 
premonitorio». Es probablemente el más complejo de los tres temas principales, el más difícil de interpretar. Si lo asociamos con el personaje de Alberto (papel interpretado por Alberto Sordi) es porque se escucha en las escenas protagonizadas por él. No hemos encontrado, por ahora, una explicación de este leitmotiv. Plantearemos una hipótesis que nos parece razonable. Alberto es, quizá, el personaje con un comportamiento más «vitellónico». Es el personaje que muestra lo trágico que resulta convertirse en un vitellone. La mayoría de sus actuaciones son completamente reprochables. Por ejemplo, la actitud hacia su hermana Olga, a la que, por un lado, pide dinero constantemente y, por otro, le reprocha su relación con un hombre casado. Otro ejemplo extremo es su burla de unos obreros con los que se encuentra viajando en coche con Ricardo y Leopoldo, burla cuyas consecuencias, además, pagan sus amigos. Creemos que también se puede plantear la hipótesis de que la película necesitaba un motivo musical con una profunda carga dramática para compensar la ligereza de los otros temas principales. Independientemente de cuál fue la intención de Rota y Fellini, nos parece claro que este tema musical contribuye a que la historia tenga una faceta de crítica social a un modo de vida reprochable. Podría ser un tema apropiado para futuros trabajos. Lo dejamos aquí para no salirnos excesivamente del objeto de nuestra investigación.

En segundo lugar, suena un fragmento del que llamaremos «Tema de Sandra y Fausto», de aire romántico y sentimental. Las sucesivas apariciones de este motivo a lo largo de la película provocarán dos efectos aparentemente contradictorios. El primer efecto sería irónico. El espectador sabe que la historia de Sandra y Fausto es cualquier cosa menos romántica. Fausto es un mujeriego sin remedio. Se casa con Sandra porque su padre le obliga, al descubrirse que la chica espera un hijo cuyo padre solo puede ser Fausto. Como era de prever, en cuanto vuelve de su viaje de novios empieza a flirtear con las mujeres atractivas que se cruzan por su camino. El segundo efecto podría ser justamente el contrario: suavizar la aspereza de la historia de Fausto y Sandra, para que se haga más llevadera.

El tercer tema es propiamente el tema de los vitelloni, una de las muestras más representativas de la música «felliniana» compuesta por Nino Rota, y con una popularidad comparable a la de los temas principales de Amarcord, La strada, Otto e mezzo o La dolce vita. Todos los analistas coinciden en que es la perfecta expresión musical de la vida fácil y carente de compromiso del adolescente eterno (Van Order, 2009, p. 42). Dado que es, sin lugar a dudas, el tema principal, puede resultar extraño que aparezca al final de los títulos de crédito, pero creemos que la razón de este orden anómalo estriba en el hecho de que en la primera escena después de los créditos es justamente lo que suena como música diegética. Empieza así a desarrollarse uno de los signos de identidad del uso del sonido por parte de Fellini: el juego de ambigüedad entre la música diegética y extradiegética 
Como explica Colón Perales (1981, p. 39), la música que es a la vez diegética y extradiegética «tiene un carácter mixto que la hace beneficiarse de las ventajas de ambos métodos. Posee la capacidad de sugestión de la música extradiegética (en cuanto a crear atmósfera) y la 'realidad de presencia' de la diegética». Colón sostiene que Fellini recurre a esta modalidad «para ambientar escenas de tipo popular, con la idea de sugerir una realidad absoluta y de dar al mismo tiempo una idea musical de lo que se representa» (Colón Perales, 1981, p. 39). Esta manera de proceder, que daría lugar a momentos de gran altura artística en películas como La dolce vita o Amarcord, tiene una primera manifestación muy destacable al comienzo de I vitelloni, cuando la música extradiegética de los títulos de crédito se convierte en diegética en una escena que sirve para presentar a los protagonistas de la película y para que la acción dé un giro dramático al descubrirse que la ganadora del concurso «Miss Sirena» está embarazada de uno de los vitelloni, Fausto (Franco Fabrizi).

Hay otros temas secundarios, como el Mambo de los Sioux o el llamado Tema del cine que tienen cierta relevancia en momentos concretos de la película, pero en los que no nos detendremos por motivos de espacio y por no ser esenciales para el objeto concreto de este estudio.

\section{LA EXPRESIÓN DEL SENTIMIENTO DE NOSTALGIA EN LA MÚSICA DE I VITELLONI}

En las páginas precedentes hemos ido adelantando algunas anotaciones que nos pueden llevar a intuir que la música de I vitelloni expresa nostalgia. Veamos ahora de un modo más concreto y resumido, a modo de conclusión, cómo se consigue esa expresión del sentimiento de nostalgia por medio de la música.

Como hemos ido viendo a lo largo del capítulo, la música de I vitelloni tiene tres pilares fundamentales. Los dos más claros serían el «Tema de Fausto y Sandra» y el «Tema de I vitelloni». Cada uno refleja ideas opuestas. Cambiar de un tema a otro refleja la tensión de los protagonistas, que, en el fondo, son conscientes de que su estilo de vida no es recomendable. Por eso, cuando Alberto tiene un desgarrado ataque de sinceridad como consecuencia de su embriaguez, va dirigiéndose a sus amigos y les dice: «Debes casarte», «debemos casarnos». Como ya vimos, con frecuencia hay una especie de puente que facilita el paso de uno a otro de estos temas opuestos: es el «Tema del cine».

En los tres temas hay dos elementos del lenguaje musical que contribuyen a transmitir un sentimiento que puede ser de nostalgia si va unido a una determinada historia. En cualquier caso, expresa sentimientos en que se mezcla lo dulce con un cierto poso de tristeza. En primer lugar, la línea descendente de las notas. Sea por naturaleza o por convención, cuando una melodía desciende de las notas 
agudas hacia las graves, el oyente tiende a sentir que la música está transmitiendo sentimientos relacionados con la tristeza. Estas líneas descendentes (de agudo a grave) son un elemento común en los temas principales de la música de $I$ vitelloni. No olvidemos, además, que su presencia es constante a lo largo de la película.

El segundo elemento del lenguaje musical que contribuye a expresar el sentimiento de nostalgia es el uso del modo menor. El modo menor se diferencia del modo mayor en el momento en que aparece el primer semitono. En el modo mayor, el primer semitono aparece en el paso de la tercera a la cuarta nota de la escala (de mi a fa en la escala de do mayor), mientras que en el tono menor el primer semitono aparece en el paso de la segunda a la tercera (de re a mi bemol en el caso de la escala de do menor). El hecho de que se adelante la aparición del semitono transmite inmediatamente la sensación de que hay algo que frena, algo que pesa, un pesar, un dolor. Esa es la razón de que el modo menor transmita un sentimiento cercano a la tristeza, como es la nostalgia.

Para decirlo con más precisión, según López Quintás (2005, p. 155), «una tonalidad en modo mayor suena, en general, más decidida, fuerte, abierta, afirmativa y alegre que la tonalidad en modo menor, que da una impresión más cerrada, adusta, sombría, triste, nostálgica».

Al preguntarnos por los sentimientos que transmite la música de una película, lo más determinante será el análisis conjunto de imagen y sonido. La música se compone en función de la imagen, y cuenta con esa imagen y con otros elementos sonoros para transmitir lo que se desea transmitir en cada caso. Ya hemos visto que la música compuesta por Nino Rota para I vitelloni, considerada autónomamente, puede transmitir el sentimiento de nostalgia. Esa potencialidad se multiplica por el contenido de la historia a la que acompaña.

La música transmitirá el sentimiento de nostalgia dependiendo, entre otros factores, del grado de conocimiento que el espectador tenga de la biografía de Fellini. De hecho, la mayoría de los espectadores que ven la película tienen un mínimo grado de conocimiento de ello. Por lo tanto, serán conscientes de que Fellini está mirando hacia su propio pasado.

\section{CONCLUSIONES}

Tras el estudio llevado a cabo, las conclusiones más relevantes se resumen del siguiente modo:

- I vitelloni es la primera película dirigida por Fellini en que empieza a tener gran importancia el elemento autobiográfico.

- Dentro de este elemento autobiográfico, es de destacar la escena final, en que el personaje principal, Moraldo, deja su voz al propio Fellini para hablar del momento en que deja la ciudad de provincias en busca de 
IGNACIO SAAVEDRA INARAJA

'I VITELLONI' COMO PRIMERA ETAPA EN LA EXPRESIÓN DEL SENTIMIENTO DE NOSTALGIA

EN LA MÚSICA QUE NINO ROTA COMPUSO PARA EL CINE DE FEDERICO FELLINI

un futuro mejor, como había hecho Fellini en vísperas de la II Guerra Mundial.

- Esa faceta autobiográfica facilita la presencia del sentimiento de nostalgia, pero no es la única razón de esa presencia. También provoca nostalgia el hecho de que los protagonistas se enfrentan a encrucijadas que les obligarán a dar un rumbo a sus vidas que ya no admitirá marcha atrás.

- Nino Rota muestra por primera vez, y de un modo muy notable, su capacidad para componer una música que sirva para que la película exprese el sentimiento de nostalgia.

\section{REFERENCIAS BIBLIOGRÁFICAS}

Cohen, A. (2011). Music as a source of emotion in film. En P. N. Juslin y J. Sloboda, J. (Eds.), Handbook of Music and Emotion: Theory, Research, Applications (pp. 249-272). Oxford University Press.

Colón, C. (1994). Fellini o lo fingido verdadero. Sevilla: Alfar.

Colón, C. (1978). Nino Rota y Federico Fellini. La música en las películas de Fellini. Tesis doctoral. Sevilla: Universidad de Sevilla.

Fellini, F. (1989). I vitelloni / La strada. Milano: Longanesi \& Co. Milano.

Fellini, F. (1972). El jeque blanco / I vitelloni / La strada / Il bidone. Madrid: Alianza

Fellini, F. (1969). Il primo Fellini. Guiones de Lo sceicco bianco, I vitelloni, La strada e Il bidone. Bologna: Cappelli.

Fraile, T. (2004). Introducción a la música en el cine: apuntes para el estudio de sus teorías $y$ funciones. Salamanca. Recuperado de: https://musicaudiovisual.files.wordpress. com/2011/10/funciones-de-la-mc3basica-en-el-cine-teresa-fraile1.pdf

Grazzini, G. (1983). Interviste sul cinema. Roma: Einaudi.

Kezich, T. (2002). Fellini, la vita e i film. Milano: Feltrinelli.

Landini, A. (2001). Il cinema e la música Fellini-Rota dai documento allo schermo. Roma: Università La Sapienza.

López Quintás, A. (2005). Estética musical. El poder formativo de la música. Valencia: Rivera Editores.

Van Order, T. (2009). Listening to Fellini. Madison: Farleigh Dickinson University Press. Vilallonga, J. L. (1994). Fellini por Vilallonga. Madrid: El País / Aguilar. 